\title{
MARGINAL PRICES OF IMPROVEMENTS MADE TO BLOCKS OF FLATS: EMPIRICAL EVIDENCE FROM ROMANIA
}

\author{
Adela DEACONU a, Dorina LAZAR ${ }^{\text {b,* }}$, Anuta BUIGA ${ }^{\text {b }}$, Gheorghe FATACEAN a \\ a Department of Accounting and Audit, Faculty of Economics and Business Administration, Babes- \\ Bolyai University, Cluj-Napoca, Romania \\ ${ }^{b}$ Department of Statistics, Forecasting, Mathematics, Faculty of Economics and Business Administra- \\ tion, Babes-Bolyai University, Teodor Mihali 58-60, 400591 Cluj-Napoca, Romania
}

Received 7 April 2014; accepted 3 July 2015

\begin{abstract}
This paper examines a specific segment of the housing markets from Central and Eastern European countries, namely the stock of flats in the urban area. With focus on Romania, we emphasize the improvements made by owners and authorities, aimed to enhance the quality of life and the maintenance of old blocks of flats; are highlighted some aspects regarding the cost of these improvements. In addition, the empirical section investigates whether and to what extent the improvements made to the flats and buildings have a significant effect on sale prices and rental prices. The marginal prices of these attributes are provided by hedonic pricing models, estimated in a generalized linear model framework; gamma and log-linear regression models perform in a similar way in terms of fit and prediction accuracy. The physical condition of the building and finishing works inside the flats, as variables of interest in our models, have a significant effect on sale and rental prices, but with different intensity. A common set of significant attributes, in the hedonic models for both sale and rental price, is suggested.
\end{abstract}

KEYWORDS: Hedonic model; Flat; Sale price; Rental price; Improvements attributes; Generalized linear model

\section{INTRODUCTION}

Residential property accounts for a significant amount of homeowners' wealth, representing an important asset for most of them. In Europe, the value of properties ranges from 0.4 times the GDP in Poland to 1.78 times in France, as reported by Colleta (2013). On the other hand, there is a strong correlation between the housing market, in particular the real estate prices index, and macroeconomics (Hepsen and Vatansever 2012). Goodhart and Hofmann (2008) highlight the interdependence between housing cost dynamics and economic activity, bank credit, inflation, and the implications of house price fluctuations for monetary and public policies.

Following the pattern of other European economies in the last decade, the rapid development of real estate markets in Central and Eastern European (CEE) countries was accompanied by an upward trend in the housing prices, and the expan-

\footnotetext{
* Corresponding author. E-mail: dorina.lazar@econ.ubbcluj.ro
}

sion of bank loans. Besides fundamentals, these movements in housing prices are related to factors specific to the transition towards a functioning market economy. Huynh-Olesen et al. (2013) found that the movements in residential property prices between 1999 and 2011 were driven by economic fundamentals such as disposable income and interest rates, transition-specific factors like fast credit growth and funding through remittances, and by construction costs.

In the context of real estate market growth, an accurate valuation of residential properties became more critical, taking account of some market specific features, such as: heterogeneity of properties, highly segmented market, infrequent trading of properties, depreciation and renovation of housing over time, durability, and high transaction costs. An accurate estimate of the value of a given property avoids arbitrary measurements and is relevant for valuation companies, valuators and public authorities. This is critical even 
more as real estate investments are sensitive to local trends. According to Fabozzi et al. (2010) real estate market is more localized then other markets, with information asymmetric and economic, demographic and geographic variables are to be taken into account (Abraham, Hendershott 1996; Lamont, Stein 1999; Ghysels et al. 2007). Special emphasis was placed on establishing some measures that account of changes in the value of residential properties over time. More than half of the national statistical offices use a hedonic approach to compute the quality-adjusted house price indices (Eurostat 2013).

After 1990, the Romanian economy was heading from socialism towards a real market economy. The real estate market has grown exponentially, and evaluation of housing has become a very important issue. The empirical results concerning the effects of location and physical characteristics, and in particular of the improvements of flats and buildings on pricing, are useful for Romanian appraisals. Real estate characteristics that could influence the sell or rent decisions are the analysis criteria from the market approach and sales grid method, included in valuation approaches and agreed upon by professional institutions.

This paper focuses on a segment of the housing market, namely the stock of flats in the Romanian urban area. Our primary objective is to investigate, through the hedonic pricing models, the effect of improvements made over time to the old blocks of flats. To this end, we also highlight specific features of these improvements, and some statistics that broadly describe the housing stock from the Romanian real estate market. We applied the generalized linear models (GLM), which provide a useful framework for the estimation of the hedonic pricing models, in addition to the traditional loglinear model. The analysis includes spatial and physical characteristics of target residential properties, additional to the attributes related to the upgrading works carried out by public authorities and owners. We also tried to see whether the effect of refurbishment and modernization on price is at least as big as apartment costs of modernization. The empirical studies point out a large number of attributes that can have a significant effect on the value of residential property. Sirmans et al. (2005) provide a review of hedonic studies from the housing literature; the characteristics that often appear in hedonic pricing models fall under the following categories: structural attributes, internal attributes, external attributes, natural environmental attributes, neighbourhood and location, public ser- vices, selling factors and financing. Studies that use hedonic modelling for apartments sale price or rental price include, among others, Hoesli et al. (1997), Berry et al. (2003), Frew and Jud (2003), Wilson and Frew (2007), Kryvobokov and Wilhelmsson (2007), Song and Wilhelmsson (2010), Helbich et al. (2013).

Frew and Jud (2003) estimate the value of apartment buildings as a function of location, amenities and capitalization rate. Property prices significantly decrease with the increasing distance from the city centre. Wilson and Frew (2007) include, in a hedonic regression for rental price, a vector of flat attributes and a vector of distance variables. Kryvobokov and Wilhelmsson (2007) found that asking prices can be well explained by flat attributes and location attributes. Song and Wilhelmsson (2010) propose, in the hedonic regression for transaction prices, a large set of attributes: size of the flat, number of rooms, monthly property management fee, existence of an elevator and balcony, floor level, age of property, distance to the centre of the city, sub-markets (administrative parish), geographical position, neighbourhood attributes, and time dummies. Some other variables considered in the literature are air pollution, water pollution, noise, proximity to recreational sites or open-space, distance to CBD (central business district), crime rate, quality of schools and the availability of public transportation. Helbich et al. (2013) suggest that solar radiation is significantly capitalized into flat prices.

There is a limited number of studies which consider explicitly, in hedonic models, variables which characterise the overall physical condition of the building, thermal characteristics (as thermal insulation, heating system) and finishing level of flats. Usually, the age of the property is considered a proxy for depreciation (Rehm et al. 2006). Brouen and Kok (2011) estimate a hedonic regression for a large sample of residential dwellings from the Netherlands, considering, among other attributes, thermal and quality characteristics (central heating, insulation, exterior maintenance). As the empirical results suggest, these attributes have a positive effect on pricing: the existence of central heating increases transaction prices by $1.4 \%$, while high-quality exterior maintenance of the property receives a price premium of $2.7 \%$.

Helbich et al. (2014) observe that an overall poor condition of dwellings leads to a drop in transaction prices of about $4 \%$, whereas a poor heating system reduces the price by $10 \%$, using housing data for Austria. The condition of the 
apartment (poor, moderate or good) is an intrinsic characteristic in the hedonic regression conducted by Herath et al. (2015); a better quality of an apartment has a significant positive impact on pricing. Bala et al. (2014) consider the type of heating system, insulation, quality index, energy source used for heating, dummy for renovated dwellings, in a hedonic regression for rental prices. The authors find that renovated and recently built dwellings along with dwellings with individual central heating have higher monthly rents. The studies of Rehm et al. (2006), Wilhelmsson (2008) and Selim (2009), among others, also include thermal or quality characteristics in hedonic modelling. The improvements made to blocks of flats increase their thermal performance.

Recent literature investigates the willingness to pay for energy efficiency. Brounen and Kok (2011) study the effects of energy performance certification on the transaction process in the Netherlands; the hedonic regressions suggest that dwellings with green energy labels receive an average price premium of about $3.6 \%$. Fuerst et al. (2015) examine the capitalisation of energy efficiency into dwelling prices in England, and empirical results confirm a positive relationship between prices and the energy performance rating of a dwelling, finding significant positive premiums for dwellings rated $\mathrm{A} / \mathrm{B}(5 \%)$ or $\mathrm{C}(1.8 \%)$ compared to dwellings rated $\mathrm{D}$.

In the following, Section 2 examines some specific features of the Romanian residential property market, highlighting the improvements made to blocks of flats over time. Section 3 reviews the advances of econometric approaches to the hedonic pricing models and points out several issues which may support the usefulness of generalized linear models. In Section 4 we present two empirical research works, one for sale transactions and another for rental transactions, which measure the implicit marginal prices of modernisations made to blocks of flats. Section 5 provides the overall conclusions of our study.

\section{THE ROMANIAN RESIDENTIAL MARKET: SPECIFIC ISSUES AND STATISTICS}

\section{Specific features of residential properties}

Similarly to other CEE countries, Romania inherits some stock of low-quality housing, consisting of blocks of flats that are undergoing a deterioration process (Palacin, Shelburne 2005). Most owners are low-income earners who have frequently resorted to bank loans in order to improve the flat's physical condition. Some public programs for housing maintenance have also been initiated. This section provides an overview of the Romanian residential market, with focus on the housing stock features and prices.

In Romania, the number of conventional dwellings per 1,000 inhabitants reached a level of about 425 , relative to about 8.5 million conventional housing units and to a stable population of slightly more than 20 million, as determined by the 2011 Population and Housing Census (National Institute of Statistics 2011). A large part of the population, i.e. $96.6 \%$ in 2012 , lives in owner-occupied flats (Eurostat 2014). The ownership ratio is generally high in Eastern European countries (86.8\% in the new member states of the European Union), following the privatization of the housing stock during the transition to a market economy. In Romania, as Pasztor and Peter (2009) point out, only few owners bought flats on the free housing market; many bought flats from the state, mostly in early $1990 \mathrm{~s}$, at a low price. Due to the high number of owners, the rental market is quite limited compared to rental markets in developed countries. The ratio of Romanians living in rented flats is rather small (3.4\%), nearly ten times lower than in the Euro Area EA18.

The population who lives in flats accounts for about $37.8 \%$ of the total population, mostly in buildings with ten or more flats $(34.2 \%)$; in large cities these proportions are higher. In recent years, the population living in flats has lightly dropped from $38.6 \%$ in 2007 to $37.8 \%$ in 2012 , showing a slight migration from flats to houses with gardens. A significant part of the urban population lives in blocks of flats built before 1990, during the communist regime. The housing stock built between 1945 and 1990 counted 6.1 million dwellings, as revealed by the 2002 Census (National Institute of Statistics 2002), while about 854 thousands new dwellings were recorded between 1990 and 2012. The period subsequent to 2008 marked a sudden fall in the number of new dwellings, by $34.5 \%$ in 2012 compared to 2008 , according to the National Institute of Statistics. The quality of the housing conditions is among the lowest in the European Union, with an overcrowding rate of $51.6 \%$, as opposed to $11.8 \%$, recorded in EU18; generally, this rate is higher (41.8\%) for the EU new member states. The average living area per person is about $20 \mathrm{~m}^{2}$, according to the 2011 Census (National Institute of Statistics 2011). 
In what concerns the residential property market, more transparency in real estate is needed. We point out the scarcity of primary and official data for the real estate transactions and sale / rental prices. Several real estate brokers and appraisers have started to collect their own data; however, the details of many transactions are not publicly available. The National Agency for Cadastre and Land Registration publishes the monthly number of real estate transactions. According to these data, the number of transactions decreased in 2009 compared to 2008 , and the following years recorded a slightly increasing trend, with percentages varying from one year to another, reaching a total of about 825 thousands transactions in 2013 , which indicates a transaction rate of around $10 \%$ per dwelling. This rate is overestimated due to the content of the indicator transaction, which includes, besides sale and purchase operations, inheritance, donation and other operations that imply transfer of ownership. On the residential market, owners usually sell their property in order to buy another. Due to the high cost of utilities (especially electricity and gas), low-income householders were compelled to move into cheaper dwellings, as also pointed out by Palacin and Shelburne (2005). In Romania, the mortgage rate is lower than in Central Europe; the residential mortgage debt to GDP ratio was of $6.6 \%$ in 2012 (European Mortgage Federation 2012). The First Home owner program launched by the Government in 2009, addressing young families in particular, was meant to incentivize the residential housing market.

Since 2009, the National Statistical Institute has been publishing a residential property price index. The data are collected from notary offices, and the price represents the value declared by both transacting parties. The recorded price is usually lower than the price actually paid, due to the fact that the transaction fee is price-dependent; a similar observation was noted by Kryvobokov and Wilhelmsson (2007) in relation to the Ukrainian real estate market. The residential property prices index is estimated using a hedonic approach. The methodology of the National Statistical Institute uses the following characteristics of the property: location, year of construction, floor area, floor of the flat, land area, the presence of a garage, comfort level, heating type, type of finishing, state of maintenance. The price of flats fell by $28.4 \%$, and that of houses by $19.6 \%$ in the third quarter of 2013 compared to 2009.

Some information about the level and dynamics of the asking prices of flats is provided by the real estate website imobiliare.ro, one of the bestknown websites that collects advertisements posted by real estate agents and owners (Realmedia Network 1999-2014). The average asking price of flats was close to 900 Euros $/ \mathrm{m}^{2}$ in December 2013. Compared to the same month in 2008 and 2009, the average price decreased by $42 \%$ and respectively $27 \%$. In the first months of 2008 the average price per $\mathrm{m}^{2}$ reached the historical high of about 2000 Euros. From late 2011 till the end of 2012, the reference period of the sale and rental transactions data collected for our empirical studies, the market prices remained relatively stable.

\section{Features of housing improvements}

In Romania, the housing refurbishment and upgrading works were made mainly from public funds. Most blocks of flats built before 1990 offer a small living surface and low comfort. In response to the continuous degradation of the buildings, some rehabilitation programs were initiated, such as thermal (and acoustic) insulation of blocks. The main program is a national thermal rehabilitation program that was implemented for blocks of flats built between 1950 and $1990^{1}$. The objectives of the program were to reduce maintenance costs, including the cost of thermal energy, and to improve indoor comfort. Another path of modernization pursued by the public authorities in the last decade was to improve the physical state of buildings. According to the Romanian appraisers, this includes the building maintenance, sewerage system, exterior coating, and physical damages due to the old age of the building.

Other refurbishment and upgrading works were made by the owners. As regards the heating system, in recent years owners have started to disconnect from the district heating system, which uses coal and heavy fuel oil, and shifted to individual heating systems (individual boiler) using natural gas, which is less expensive. Around 1.55 million dwellings are connected to the district heating system (18\% of the conventional housing stock), most of them flats (BPIE 2014). To improve the comfort and utility of the living space, a large number of owners carried out some finishing works in their homes, consisting of repairing, maintenance, and alterations. These improvements range from

\footnotetext{
1 The EU regulations, e.g. the 2006/32/EC EU Directive, require the improvement of energy end-use efficiency. According to the Government Ordinance (2009) on the increase of energy performance in blocks of flats built between 1950 and 1990, the related costs are covered as follows: $50 \%$ subsidised from the state budget, $30 \%$ by local public authorities, and $20 \%$ by owners' association.
} 
replacing windows, installing individual heating, improving the plumbing, renovating to remodelling the flat, and are meant to enlarge the living space or reduce the cost of utilities.

In terms of refurbishment and upgrading costs, for the first level, namely thermal rehabilitation, the most relevant are the provisions related to the national program laid down by Government Ordinance (2009). This program was regulated by the Government Decision (2010) that took into account the cost standard for public investments. According to this act, the upgrading cost is of $55 \mathrm{Euro} / \mathrm{m}^{2}$ for one or two-room flats, with a functional area from 37 to $52 \mathrm{~m}^{2}$. The second level of upgrading costs involves the physical condition of the block of flats itself. Technical references ${ }^{2}$ for the year 2011 indicate a total cost of about $87 \mathrm{Euro} / \mathrm{m}^{2}$ functional area, without VAT. The elements involved are the heating equipment, exterior finishing and interior (staircase) finishing. The third level of upgrading costs is related to the interior of the flat. According to the same catalogue cited for the modernization of blocks, the finishing works cost about 37 Euro/ $\mathrm{m}^{2}$ functional are $\mathrm{a}^{3}$, without VAT as an average for one or two-room flats.In the empirical section, we study the effect of thermal insulation, overall physical condition of the blocks of flats, and finishing works inside the flats on sale and rental prices, while drawing a comparison between the sale prices and the costs presented above.

\section{ECONOMETRIC APPROACHES OF THE HEDONIC PRICING MODEL}

Hedonic regression has become the preferred method applied to estimate the marginal effect of an attribute on real estate pricing. The theory of hedonic prices was developed by Rosen (1974), in a general framework of competitive market equilibrium, for the class of products described by a

\footnotetext{
${ }^{2}$ According to the catalogue prices of Şchiopu (2011) and comparing the superior status with the normal status, the partial costs per modernization elements are expressed in Euro/m², in 2011 prices (1 Euro $=4.28$ Lei): 11 for heating equipment, 63 for exterior finishing and 13 for interior (staircase) finishing; the calculus is the same for blocks with Ground floor + 4floors + Technical basement and respectively Ground floor+8floors+Technical basement; for interior (staircase) finishing for which the data is reported in the catalogue for the overall work, we made the calculation for a flat with an average area of $44 \mathrm{~m}^{2}$, and 4 flats per floor.

3 The catalogue for prices reflects the cost of the overall work, for one-room flats (with area of $36 \mathrm{~m}^{2}$ ) and for two-room flats $\left(52 \mathrm{~m}^{2}\right)$.
}

finite set of observable attributes; it is assumed that "goods are valued for their utility-bearing attributes or characteristics". In the residential housing market framework, the overall value of a property is assumed to be determined by a set of constitutive intrinsic attributes embedded into the property. The interaction between supply and demand determines the implicit marginal prices (marginal willingness to pay for each attribute).

The relation between property price $P$ and the observable characteristics of the property $X_{1}, X_{2}, \ldots X_{k}$ is given by the hedonic price function $f$. Microeconomic theory gives little guidance in choosing a priori an appropriate functional form. Rosen (1974) observed that there is no theoretical reason for the hedonic function to be linear. Ekeland et al. (2004) conclude that the hedonic model is generically nonlinear, and the linearization strategies, made to simplify the estimation, can generate identification issues. The log-linear functional form is the most commonly used specification in hedonic housing price models; this approach is based on the assumption that the distribution of prices is close to a log-normal distribution. The log-transformation is applied in order to bring the distribution closer to normality, and to stabilize the error term variance, therefore to reach the assumptions of the classical linear regression model.

Econometric tools applied to estimate the hedonic model should take into account the statistical properties of the data. The real estate reporting takes into account the fact that the house price distributions are generally positively skewed, as long as the median price is typically used as a measure of central tendency (Eurostat 2013). Some recent papers use a quantile hedonic regression approach. Zietz et al. (2008), among others, use the quantile regression methodology to estimate the marginal contribution of house attributes to pricing, for different points in the distribution of prices. On the other hand, homoscedasticity is one of the most restrictive assumptions of the traditional least squares approach (OLS), used to estimate the linear/ log-linear hedonic price model. When the variance of the error term depends on the property attributes in a systematic way, the OLS estimation leads to biased estimated standard errors and therefore to biased inference on the coefficients. Among the causes of heteroscedasticity in hedonic models, the literature highlights the age of the property, living area (Stevenson 2004), spatial heterogeneity (Helbich et al. 2014). 
In the context of non-normality distribution of prices and heteroscedasticity issues, the generalized linear model framework is useful to estimate the hedonic equation (McCulloch, Searle 2001). The generalized linear models provide some flexibility in what concerns the house price distributions and variance assumptions. A function $g$ links the conditional mean of response variable $E(Y \mid X)=\bar{Y}$ to the linear predictor:

$$
g(\bar{Y})=\beta_{0}+\beta_{1} X_{1}+\beta_{2} X_{2}+\ldots+\beta_{k} X_{k},
$$

where: $k$ is the number of explanatory variables. The response variable $Y$ follows a distribution that belongs to the large class of exponential family distributions ${ }^{4}$. Specification of a GLM model requires an appropriate distribution for dependent variable, and a link function. In the empirical section, we draw a comparative analysis across the GLM models, under some common assumptions on the price distribution, as log-normal, Gamma, and inverse Gaussian distributions.

The robustness of empirical results is investigated from several points of view: a) for dependent variable were considered alternative distributions respectively log-normal, Gamma and inverse Gaussian, b) some misspecification issues are addressed, namely the multicollinearity and omitted variables, c) the White's heteroscedasticity-consistent estimator is used, to take account of a possible heteroscedasticity in data.

\section{EMPIRICAL RESULTS FOR SALE PRICES AND RENTAL PRICES}

\subsection{Flat attributes and data set}

The data set was collected from several real estate agents in September-December 2011, and then in the same period of 2012 , and covers the sale and rent transaction prices, along with the structural attributes of the flats; the sample size for reported regressions is of 483 sale transactions and 468 rental transactions. On the Romanian market, sale and rental transactions are recorded mainly by real estate agents, such as real estate brokers and appraisal practitioners who maintain such databases. The data were collected by means of interviews with real estate agents who made the sale and rent offers public, and revealed the final transaction prices. We included in the sample flats

\footnotetext{
4 The exponential family includes continuous distribution, as normal, Gamma, inverse Gaussian, Pareto, lognormal, exponential distribution.
}

with one and two rooms, since the transactions involving these types of flats are the most frequent.

The hedonic models estimated in our paper incorporate two spatial flat attributes, in order to take account of the regional and locational price differences. The data set comes from four large cities, namely Cluj-Napoca, Iasi, Timisoara, and Arad, which are representative for three regions of the country: North-East, West and North-West ${ }^{5}$. The first three cities mentioned are the largest in the country, after Bucharest - the capital of Romania ${ }^{6}$. The second characteristic is the location of the flat inside the city. This variable is defined by four categories: central district, intermediate district, urban periphery district (town adjacent district or city vicinity), and suburban area. The classification into these categories takes account of the address available in the database for each flat, and then we resorted to the evaluation reports used by the $\mathrm{Na}$ tional Chamber of the Public Notaries ${ }^{7}$.

Our main goal is to quantify the implicit marginal prices for the improvements made to flats and buildings. To this end we focus on the improvement attributes: thermal insulation of the building, overall physical condition of the building, heating system, and finishing works into the flat. Thermal insulation means insulation of the building's external walls, replacement of exterior windows and doors, and roof waterproofing. The categories for the physical condition of the building

$\overline{5 \text { Romania }}$ is divided into 8 development regions, units with no legal personality, established in 1998 by the Romanian association of County Councils, for regional development coordination purposes.

6 The population of the four cities, according to the 2011 Census: 324576 inhabitants in Cluj-Napoca, 319279 in Timisoara, 290422 in Iasi, and 159074 in Arad (National Institute of Statistics 2011). These cities, and therefore the collection of data used in the paper, were part of a pilot study conducted within a European Social Fund project/The Sectorial Operational Programme for Human Resources Development 2007-2013, designed to investigate the economic environment of businesses, and assets valuation practices in Romania.

7 These reports cover the large cities of Romania and show some guidelines on property sale prices, according to their intended use (residential, industrial, commercial and office space) and type (flat, house, land), using maps to delimitate the four zones which derive from the location established in urban planning zoning; we used the reports for December 2013 and for the category of flats with a floor area between 40 and $70 \mathrm{~m}^{2}$. Their main purpose is to support the National Chamber of the Public Notaries to compute the taxable revenue resulting from the transfer of real estate. Information sources include databases developed by appraisers, professional guidebooks edited by valuation institutions, newspaper advertisements, specialized websites and real estate agencies. 
are very good - the maintenance works, current repairs and overhauls were completed in a timely manner, good - maintenance and current repairs were completed on time and on acceptable terms, but no overhauls have been performed, respectively unsatisfactory - some maintenance works were performed, but current and capital repair works were neglected. For the heating system we devised the following categories: individual heating (individual boiler) and district (central) heating.

The modernisation features usually added by the owner are included as an attribute named finishing works, falling within three categories: demi-finishing, medium-finishing, and superiorfinishing. The demi-finishing status (lower-finishing or unfinished) is usually viewed by Romanian valuators as a descriptor for old blocks of flats, built before 1990 and which need some finishing works to convert the flat into medium-finished. Demi-finishing level can be broadly described by: floor covered with parquet flooring or carpet, walls painted in lime or washable paint, double glazing or wooden windows, wood (sometimes metal) entry door, wooden interior doors, connections to utilities, sanitary ware and lighting installed (but average-lower quality), with or without individual central heating, exterior finishes of the block ${ }^{8}$.

Other characteristics of the flat are included as control variables. Controlling for the impact of other attributes is important in order to measure as accurately as possible the effect of improvements made to the flat/ block on pricing. The hedonic real estate literature highlights a large number of housing characteristics to explain the variation in sale and rental prices. Taking into account these studies and the Romanian appraisal practice, we consider a set of flat attributes, in addition to the improvement attributes, that could aid in explaining the differences in the value of flats: location within the city, number of rooms, floor area, year of construction, existence of a garage, existence of an elevator, type of flat (detached, non-detached ${ }^{9}$ ), number of building floors, floor where the flat is located, existence of a balcony, year of transaction. Table 1 describes

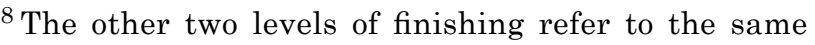
items, but of superior quality. As an example, for medium-finishing status, the floor is covered with good quality parquet flooring or carpet, and for superiorfinishing, the floor is covered with superior quality flooring.

${ }^{9} \mathrm{~A}$ detached flat is composed by several rooms each of them having direct access to a hall; when one or several rooms communicate(s) with another room, the flat is non-detached or demi-detached.
}

the variables included in the hedonic models for the sale price, respectively rental price.

In this section we present two hedonic analyses, one for sale transactions and another for rental transactions. We used a sample of flats located in the four cities mentioned above, being aware, however, of the potential differences between regions (cities) and submarkets within the city, in terms of contribution of the various attributes to the price and rent. Blackley et al. (1986), among others, found empirical evidence of the heterogeneity of prices; property value varies across metropolitan areas and time periods. Mixing data for several important Romanian cities into a single sample provides the framework for studying the inter-city housing market price differences, for a standardized dwelling (flat with one or two rooms). On the other hand, the existence of spatial housing submarkets inside the city is explained by Jones (2002) by means of factors such as search costs, transaction costs, imperfect information and inelastic supply. We take into account the existence of potential submarkets within the city by location variable (street allocation to a specific price area, according to notaries' reports).

For the hedonic model we consider the following three specifications: S1-normal distribution with identity link for natural logarithm of prices (this is the traditional log-linear model), S2-Gamma distribution with log link, and S3-inverse Gaussian distribution with log link. In a GLM framework, the models are fitted to data using the method of maximum likelihood ${ }^{10}$. We mention that for a Gamma distribution the standard deviation increases linearly with the mean, and for inverse Gaussian distribution the variance is proportional with the third power of the mean. Both distributions allow for the variance of price to increase when the price increases. As there is a strong association between the floor area and the number of rooms, only one of these attributes is included in the models; the estimated models designated as M1, M2, M3 in Table 2 and Table 3, include the number of rooms, whereas M4 and M5 consider the floor area.

\subsection{Empirical results for sale prices}

Table 1 summarizes the sample structure, the average price recorded for each attribute and

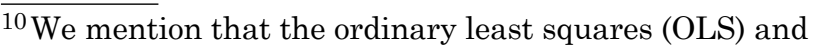
maximum likelihood estimators are asymptotically equivalent, when applied for the traditional log-linear model, therefore provide the same results.
} 
Table 1. Variables for sales price respectively for rental price models: descriptive statistics and ANOVA

\begin{tabular}{|c|c|c|c|c|c|c|c|}
\hline \multirow[t]{2}{*}{ Name } & \multirow[t]{2}{*}{ Variable } & \multicolumn{3}{|l|}{ Sales price } & \multicolumn{3}{|l|}{ Rental price } \\
\hline & & $\begin{array}{l}\text { ANOVA } \\
\text { F (p-value) }\end{array}$ & $\%$ & $\begin{array}{l}\text { Mean } \\
\text { price }\end{array}$ & $\begin{array}{l}\text { ANOVA } \\
\text { F (p-value) }\end{array}$ & $\%$ & $\begin{array}{l}\text { Mean } \\
\text { price }\end{array}$ \\
\hline Price & $\begin{array}{l}\text { Sales price of the flat (euro) } \\
\text { Rental price of the flat (euro) }\end{array}$ & & & 40590 & & & 220 \\
\hline \multicolumn{8}{|c|}{ Attributes } \\
\hline Thermal & $\begin{array}{l}\text { Thermal insulation of the block: } \\
\text { Yes } \\
\text { No (reference category) }\end{array}$ & $8.4(0.01)$ & $\begin{array}{l}59.1 \% \\
50.9 \%\end{array}$ & $\begin{array}{l}42295 \\
38948\end{array}$ & $31.6(0.00)$ & $\begin{array}{l}31.2 \% \\
68.8 \%\end{array}$ & $\begin{array}{l}256 \\
204\end{array}$ \\
\hline \multirow[t]{3}{*}{ Heating } & Heating system: & $28.5(0.00)$ & & & $22.7(0.00)$ & & \\
\hline & Individual boilers & & $62.7 \%$ & 42927 & & $45.5 \%$ & 245 \\
\hline & Central heating (reference category) & & $37.3 \%$ & 36655 & & $54.5 \%$ & 214 \\
\hline \multirow[t]{4}{*}{ Finishing } & Finishing work into flat: & $17.6(0.00)$ & & & $8.7(0.00)$ & & \\
\hline & Super finishing & & $23.4 \%$ & 42454 & & $26.5 \%$ & 241 \\
\hline & Medium finishing & & $56.3 \%$ & 42208 & & $56.8 \%$ & 220 \\
\hline & Demi-finishing (reference category) & & $20.3 \%$ & 33948 & & $16.7 \%$ & 187 \\
\hline \multirow[t]{3}{*}{ Finishing2 } & Finishing work into flat: & $35.2(0.00)$ & & & & & \\
\hline & Super finishing or medium finishing & & $79.7 \%$ & 42281 & & & \\
\hline & Demi-finishing (reference category) & & $20.3 \%$ & 33948 & & & \\
\hline \multirow[t]{4}{*}{ PhCond } & Overall physical condition: & $16.9(0.00)$ & & & $18.7(0.00)$ & & \\
\hline & Very good & & $40.2 \%$ & 44117 & & $26.0 \%$ & 261 \\
\hline & Good & & $46.4 \%$ & 39319 & & $62.0 \%$ & 204 \\
\hline & Unsatisfactory (reference category) & & $13.5 \%$ & 34441 & & $12.0 \%$ & 218 \\
\hline \multirow[t]{3}{*}{ PhCond2 } & Overall physical condition: & & & & $36.1(0.00)$ & & \\
\hline & Very good & & & & & $26.1 \%$ & 260 \\
\hline & Good and unsatisfactory (ref. cat.) & & & & & $73.9 \%$ & 206 \\
\hline \multirow[t]{5}{*}{ City } & The city: & $8.9(0.00)$ & & & $30.1(0.00)$ & & \\
\hline & Arad & & $15.5 \%$ & 34383 & & $8.0 \%$ & 152 \\
\hline & Iasi & & $25.3 \%$ & 39596 & & $25.6 \%$ & 242 \\
\hline & Timisoara & & $31.7 \%$ & 42522 & & $39.3 \%$ & 191 \\
\hline & Cluj-Napoca (reference category) & & $27.5 \%$ & 42778 & & $21.1 \%$ & 262 \\
\hline \multirow[t]{4}{*}{ Location } & Location in the city: & $11.7(0.00)$ & & & $30.3(0.00)$ & & \\
\hline & Central and intermediate district & & $44.5 \%$ & 42904 & & $21.6 \%$ & 275 \\
\hline & Urban periphery district areas & & $32.5 \%$ & 40798 & & $33.1 \%$ & 217 \\
\hline & Suburban areas (reference category) & & $23 \%$ & 35813 & & $45.3 \%$ & 196 \\
\hline Rooms & Number of rooms: & $137.5(0.0)$ & & & $49.0(0.00)$ & & \\
\hline & Two rooms & & $71.2 \%$ & 44433 & & $67.5 \%$ & 239 \\
\hline & One room (reference category) & & $28.8 \%$ & 31078 & & $32.5 \%$ & 180 \\
\hline Floor & Floor level: & $2.2(0.11)$ & & & $1.63(0.20)$ & & \\
\hline & Ground floor & & $15.5 \%$ & 40162 & & $16.5 \%$ & 204 \\
\hline & Intermediate & & $67.3 \%$ & 41337 & & $67.9 \%$ & 223 \\
\hline & Last floor (reference category) & & $17.2 \%$ & 38052 & & $15.6 \%$ & 228 \\
\hline Floor2 & Floor level: & $3.4(0.07)$ & & & & & \\
\hline & Intermediate & & $67.3 \%$ & 41337 & & & \\
\hline & Ground or last floor (ref. cat.) & & $32.7 \%$ & 39054 & & & \\
\hline Area & Floor area $\left(\mathrm{m}^{2}\right)$ & & & & & & \\
\hline Year & Year of construction: & $0.9(0.34)$ & & & $27.0(0.00)$ & & \\
\hline & 1990 & & $36 \%$ & 41372 & & $16.7 \%$ & 271 \\
\hline & $<1990$ (reference category) & & $64 \%$ & 40144 & & $83.3 \%$ & 211 \\
\hline Garage & Existence of a garage: & $20.6(0.00)$ & & & $113.7(0.00)$ & & \\
\hline & Yes & & $10 \%$ & 48515 & & $9.0 \%$ & 346 \\
\hline & No (reference category) & & $90 \%$ & 39736 & & $91.0 \%$ & 209 \\
\hline NoFloors & Number of floors of the block: & $2.5(0.10)$ & & & $19.5(0.00)$ & & \\
\hline & $>5$ floors & & $31.9 \%$ & 41934 & & $27.1 \%$ & 245 \\
\hline & 5 (reference category) & & $68.1 \%$ & 39961 & & $72.9 \%$ & 208 \\
\hline Type & Type of flat: & $20.1(0.00)$ & & & $1.8(0.18)$ & & \\
\hline & Detached & & $70.6 \%$ & 42251 & & $66.8 \%$ & 230 \\
\hline & Not-detached (reference category) & & $29.4 \%$ & 36602 & & $33.2 \%$ & 218 \\
\hline Elevator & Existence of an elevator: & $2.6(0.11)$ & & & $19.2(0.00)$ & & \\
\hline & Yes & & $36.9 \%$ & 41822 & & $27.4 \%$ & 249 \\
\hline & No (reference category) & & $63.1 \%$ & 39871 & & $76.2 \%$ & 211 \\
\hline Balcony & Existence of balcony: & $12.2(0.00)$ & & & $20.1(0.00)$ & & \\
\hline & Yes & & $65.4 \%$ & 42056 & & $63.7 \%$ & 234 \\
\hline & No (reference category) & & $34.6 \%$ & 37851 & & $36.3 \%$ & 196 \\
\hline Year_tr & Year of transactions & $0.9(0.33)$ & & & $3.5(0.07)$ & & \\
\hline & 2011 & & $53.6 \%$ & 41115 & & $50.9 \%$ & 227 \\
\hline & 2012 (reference category) & & $46.4 \%$ & 39983 & & $49.1 \%$ & 213 \\
\hline
\end{tabular}


category and also the results from the analysis of variance (ANOVA) method. For the entire sample, the average sale price is of 40590 Euros, with a standard deviation of 12834 Euros. The distribution of prices has a positive skew and is platykurtic. Two-room flats (71.2\%), with an average floor area of $52 \mathrm{~m}^{2}$, prevail; for one-room flats the average floor area is about $36 \mathrm{~m}^{2}$. Most transactions seemed to occur in the three largest cities, respectively Cluj (27.5\%), Iasi $(25.3 \%)$ and Timisoara (31.7\%). A large part of the flats are located in blocks with less than 5 floors, built before 1990, and without elevators.

The attributes measuring the improvements made to the flat or building are encoded as Thermal, Heating, Finishing, and physical conditions as PhCond. A large part of the blocks were built before 1990, but their average price does not seem to be significantly lower than that of newer flats, revealing potential improvements to the old blocks. About $80 \%$ of the flats have undergone interior finishing works, $23.4 \%$ being superior-finished and $56.3 \%$ medium-finished. Examining the modernisation features of the blocks, namely physical condition and thermal insulation, it can be noted that a large number of the flats are in good or very good state in terms of overall physical condition; 59\% of the blocks were included in thermal rehabilitation programs. The values for the variable heating system confirm our preliminary descriptions concerning the prevalence of flat owners who decided to quit the district heating in favour of individual boilers. We mention that these statistics are drawn from our sample, without being generalised to the entire market. The data indicates, however, that some efforts were made during the last two decades on the housing market to improve the physical state and comfort of blocks of flats.

As a preliminary analysis, we examined each attribute separately and computed the F-test from ANOVA, presenting the results in Table 1. The null hypothesis that the average prices are equal across the groups is rejected for all improvement attributes, except for thermal insulation, which is borderline rejected ( $\mathrm{p}$-value $=$ $0.011)$. Therefore the average price seems to vary across the categories, for the physical condition of the building, degree of finishing, and heating system. As regards the control attributes, the null hypothesis is rejected for the age of the building (before/after 1990) and year of transaction, and borderline rejected for the number of floors in the building, flat floor, existence of an elevator. The transaction dates cover the period from late 2011 to 2012 , during which the market prices remained relatively stable, therefore we expected this conclusion for the year of transaction. Upon examination of the $F$ statistic, the city does not seem to hold a very high explanatory power for the price; as the descriptive statistics suggest, except for Arad where the average price is significantly lower, the average prices for the other three large cities are comparable to each other.

The entire sample (sample size is 483 transactions) will be used to estimate the hedonic pricing models. Table 2 contains the variables with significant effect on the sale price, for each of the five models, which were estimated using the maximum likelihood method. A backward selection approach has been applied. All attributes were included in the model, then the attribute with the highest $p$ value was removed, and the new specification was estimated, and these steps were repeated until all coefficients had a p-value lower than $0.1^{11}$. For the Finishing variable, the coefficient of dummy associated to medium finishing is not significant, therefore this variable has been redefined as a dummy with two categories Finishing2, as shown in Table 1. In a similar manner, the variable Floor was redefined as Floor2; there is no significant difference between the prices of flats located on the top floor compared to the ground floor. Also, due to few flats being sold in the central area, for some cities, the central district and intermediate district locations are compressed into a single category.

An overall goodness-of-fit is indicated by the likelihood ratio test. The Wald chi-square test is applied to test the statistical significance of each coefficient. The empirical results seem to be consistent with different specifications for GLM; generally the same explanatory variables were retained as having significant coefficients. Estimates obtained for marginal effects in Gamma-log M2 and inverse Gaussian-log M3 are close to those provided by the traditional hedonic log-linear M1 model. In the framework of maximum likelihood method, the coefficient $R^{2}=1-D_{1} / D_{0}$, where $D_{1}$ is the residual deviance for the estimated model and $D_{0}$ the residual deviance for the model including only the intercept, measures the proportion of the null deviance accounted for by the model (Fox 2008). These coefficients suggest a medium goodness-of-fit for our models; a similar value of this coefficient is obtained for traditional log-linear

\footnotetext{
${ }^{11}$ The empirical results for models including all attributes can be provided upon request.
} 
Table 2. Summary of hedonic models for sales price

\begin{tabular}{|c|c|c|c|c|c|}
\hline Model & M1 & M2 & M3 & M4 & M5 \\
\hline Variable & Log-linear & Gamma-log & In.Gauss-log & Log-linear & Gamma-log \\
\hline Finishing2 & $1.099 *(9.4)$ & $1.084^{*}(7.4)$ & $1.096 *(8.3)$ & $1.095^{*}(10.5)$ & $1.077 *(8.4)$ \\
\hline \multicolumn{6}{|l|}{ PhCond } \\
\hline Very good & $1.154 *(12.9)$ & $1.149 *(13.3)$ & $1.183^{*}(16.3)$ & $1.150 *(15.7)$ & $1.127^{*}(41.7)$ \\
\hline Good & $1.078 *(4.4)$ & $1.057(2.9)$ & $1.081^{* *}(4.5)$ & $1.091 *(7.0)$ & $1.056^{*}(15.4)$ \\
\hline Heating & $1.062^{* *}(4.6)$ & $1.062 * *(4.9)$ & $1.067 * *(4.6)$ & - & - \\
\hline \multicolumn{6}{|l|}{ City } \\
\hline Arad & $0.750 *(58.0)$ & $0.752 *(58.9)$ & $0.736^{*}(54.3)$ & $0.729 *(74.4)$ & $0.738^{*}(93.6)$ \\
\hline Iasi & $0.941(3.4)$ & $0.962(1.4)$ & $0.959(1.2)$ & $0.972(0.9)$ & $0.994(0.3)$ \\
\hline Timisoara & $0.963(1.3)$ & $0.951(2.2)$ & $0.941(2.4)$ & $0.955(2.4)$ & $0.944(3.0)$ \\
\hline \multicolumn{6}{|l|}{ Location } \\
\hline Central and interm. & $1.270 *(56.9)$ & $1.250 *(52.4)$ & $1.260 *(44.8)$ & $1.217 *(45.7)$ & $1.192 *(41.9)$ \\
\hline Urban periphery district & $1.191 *(27.8)$ & $1.177 *(24.8)$ & $1.199 *(23.6)$ & $1.138 *(17.6)$ & $1.117 *(14.5)$ \\
\hline Rooms & $1.44 *(218.4)$ & $1.419 *(213.5)$ & $1.424 *(184.9)$ & - & - \\
\hline Area & - & - & - & $1.017 *(375.1)$ & $1.018 *(438.6)$ \\
\hline Garage & $1.118 *(8.1)$ & $1.115^{*}(8.1)$ & $1.114^{*}(5.1)$ & - & - \\
\hline NrFloors & $1.061^{* *}(4.9)$ & $1.046(3.06)$ & $1.058(3.5)$ & - & - \\
\hline Type & $1.121 *(20.1)$ & $1.120 *(21.1)$ & $1.120 *(16.8)$ & $1.041^{* *}(2.8)$ & - \\
\hline Balcony & $1.090 *(12.2)$ & $1.080 *(10.3)$ & $1.081 *(8.4)$ & $1.067 *(8.1)$ & $1.061^{*}(7.3)$ \\
\hline Elevator & - & - & - & $1.062^{* *}(6.1)$ & $1.057 * *(6.2)$ \\
\hline Floor2 & - & - & - & $1.066^{*}(8.1)$ & $1.061 *(8.1)$ \\
\hline \multirow[t]{5}{*}{ Intercept } & $18688.2^{*}$ & $20216.7^{*}$ & $19382.8^{*}$ & $12381.2^{*}$ & $13017.0^{*}$ \\
\hline & $\mathrm{LR}=367.0^{*}$ & $\mathrm{LR}=345.89^{*}$ & $\mathrm{LR}=285.8^{*}$ & $\mathrm{LR}=448.4^{*}$ & $\mathrm{LR}=466.53$ \\
\hline & $\mathrm{AIC}=13.6$ & $\mathrm{AIC}=10193.9$ & $\mathrm{AIC}=10322.5$ & $\mathrm{AIC}=-69.1$ & $\mathrm{AIC}=10061.4$ \\
\hline & $\mathrm{MAE}=6329.3$ & MAE $=6319.5$ & $\mathrm{MAE}=6431.2$ & $\mathrm{MAE}=5472.1$ & $\mathrm{MAE}=5463.2$ \\
\hline & $\mathrm{R} 2=0.54$ & $\mathrm{R} 2=0.50$ & $\mathrm{R} 2=0.45$ & $\mathrm{R} 2=0.61$ & $\mathrm{R} 2=0.62$ \\
\hline
\end{tabular}

Notes: For each model are reported $\operatorname{Exp}(\beta)$ where $\beta$ are the coefficients of explanatory variables, and the Wald test (in parentheses). ${ }^{*}$ Significant at $1 \%,{ }^{* *}$ significant at $5 \%$. For inverse Gaussian-log model including the Area are obtained: $\mathrm{LR}=398.4, \mathrm{AIC}=10205.9, \mathrm{MAE}=5936.2, \mathrm{R} 2=0.56$.

model $^{12}$. To compare the (in-sample) performance of the three models, we also considered the differences between observed and predicted prices, and computed the mean absolute error $\mathrm{MAE}^{13}$. This measure suggests that Gamma-log model M2 provides a slightly better agreement between observed and predicted prices than M1 and M3. The Akaike information criterion (AIC) ${ }^{14}$, R-square and MAE usually suggest that the Gamma-log model performs better than the inverse Gaussian-log model, in terms of goodness-of-fit and prediction accuracy.

Examining the estimated coefficients from Table 2 , where are indicated $\exp (\beta)$, the attributes have the expected signs. The percentage effect of an attribute over the price is given by $[(\exp (\beta)-1] \cdot 100$. As regards our primary goal, to measure the effect of the improvement attributes

\footnotetext{
${ }^{12} \mathrm{We}$ mention that the traditional R-square coefficient, computed for the log-linear model estimated by OLS has the same values, respectively $\mathrm{R} 2=0,54$ for $\mathrm{M} 1$ and $\mathrm{R} 2=0.61$ for $\mathrm{M} 4$, when the same regressors, as in Table 3, are included.

${ }^{13}$ Willmott and Matsuura (2005) suggest that MAE is better suited than the Root Mean Squared Error to measure the model performance.

${ }^{14}$ The AIC cannot be used to compare M2 and M3 models with the traditional log-linear model M1, as long as in the log-linear model the prices were transformed, being thus on different scales.
}

on pricing, the physical condition of the building and the finishing variables have a significant effect on the price in all specifications. As the log-linear model seems to perform slightly better, in terms of $\mathrm{R}$-square coefficient, we look at the implicit marginal prices provided by M1. Thus, the prices of flats located in buildings that are classified as good and very good are higher by $7.8 \%$ and by $15.4 \%$ respectively than the prices of flats from buildings with unsatisfactory technical conditions. The finishing works inside the flat determines price increases of $10 \%$. These findings are in line with the empirical results from other studies. The market prices of flats and houses in which changes and renovations were undertaken appear to be higher (Portnov et al. 2005; Kryvobokov, Wilhelmsson 2007; Sipos, Crivii 2008; Herath et al. 2015).

The marginal effect of the heating system is borderline significant. There is a willingness to pay a price approximately $6 \%$ higher for the existence of an individual boiler heating system. The thermal insulation dummy does not have a significant coefficient, but this characteristic may be viewed as embedded into the physical condition of the building. If the physical condition of the building is not included in the model, the Thermal variable has a significant effect on pricing, at $5 \%$ significance level $($ Wald test $=4.15 ; \mathrm{p}$-value $=0.04$ ) 
The chi-square test supports this remark, a significant degree of association being observed between the PhCond and Thermal variables (chi-square statistic $=168.0$ and $p$-value $=0.00$; the contingency coefficient $=0.51$ ).

On the other hand, as expected, the number of rooms has the highest explanatory power. The price of two-room flats is $44 \%$ higher than the price of one-room flats. Location inside the city also has a significant effect on pricing. The flats from blocks located in the central district, intermediate district and urban periphery district areas have a significantly higher price than those from suburban areas, by $19 \%$ and $27 \%$ respectively. If we compare the prices in the four cities, we find, as expected, significantly lower prices in Arad (by about 25\%) than in Cluj-Napoca. For Iasi and Timisoara, the conclusion is not so clear, as there seems to be no significant differences in prices compared to Cluj-Napoca; in these two cities the price does not appear to be significantly different, as also suggested by the Student t-test for equality of two means $(t=0.18$; $p$-value $=0.85)$. The coefficients of corresponding dummy variables seem to be insignificant in some specifications; therefore, they must be interpreted with caution. Generally the coefficients for dummies for cities should be only interpreted as indicative, due to the small sample of transactions from each city. The other structural characteristics, namely the existence of a balcony and a garage, detached flats, have a positive effect on the price. Flats located in high blocks (more than 5 floors) seem to be more expensive than those from blocks with fewer floors. The four-floor blocks are generally old buildings; therefore, this attribute may incorporate partial information about the age of the building.

We conducted a similar empirical analysis for hedonic regressions, considering the floor area instead of the number of rooms. A backward selection approach was applied for the same specifications as above (S1-normal distribution with identity link for logarithm of prices, S2-Gamma distribution with log link, and S3-inverse Gaussian distribution with log link). Table 2 reports the results for the Log-linear model denoted by M4 and for the Gamma-log denoted by M5. For inverse Gaussian specifications, not reported here, we obtained a lower value for $\mathrm{R}$-square and a higher value for MAE, than for M4 and M5. In terms of fit and prediction accuracy the Gamma-log model (M5) performs slightly better than the log-linear model (M4). We can see that the floor area has a positive and high significant effect on pricing; one additional square meter raises the flat's price by $1.8 \%$, as long as the other attributes are the same. The physical condition of the building and finishing variable have a significant impact on the sale price, and the estimated coefficients are close to those obtained from models which include the number of rooms as an explanatory variable. If the physical condition of the building is removed from the models, the thermal insulation becomes a significant attribute for the sale price (Wald test $=9.07$; -value $=0.00$ ), therefore the overall physical condition variable seems to capture the effect of thermal insulation. The other structural characteristics, with positive effect on pricing are: existence of a balcony, floor number, detached flats, and existence of an elevator.

Therefore, the physical condition of building and the finishing works into the flat have a significant effect on sale prices for all distributions considered for sale price (log-normal, Gamma, inverse Gaussian); our results are robust to the distribution of sale price. On the other hand, the multicollinearity is often an issue in regression models. The Variance Inflation Scores (VIF), a measure usually used for detecting the presence of multicollinearity, not exceeds 3.28 for any explanatory variables, suggesting that the multicollinearity is not a major problem. Although no definitive rules exist for the threshold of VIF, the general approach is that multicollinearity is not a serious problem if the VIF not exceed 5 (Troy, Grove 2008). A likelihood ratio (LR) test for omitted variables is also conducted. According to LR statistic, the physical state of the building (LR = 9.36, $p$-value $=0.00$ for model M1, and LR $=13.2$, $p$ value $=0.00$ for model M4) and the finishing works $(\mathrm{LR}=10.5$, $\mathrm{p}$-value $=0.01$ for model M1, and $\mathrm{LR}=$ 15.6 , $\mathrm{p}$-value $=0.00$ for model M4) have a significant contribution to explaining the variation in the sale price. Regarding the heteroscedasticity issue, in order to avoid a potential bias in the variance of estimated parameters, has been used the White's heteroskedasticity consistent covariance matrix estimator (White 1980). The provided results were similar to the reported ones; our variables of interest have significant coefficients.

\section{Empirical results for rental price}

For our sample of 468 rental transactions, the average monthly rental price is of 220 Euros, with a standard deviation of 90 Euros. Table 1 indicates the percentage of transactions and average rental price determined for each attribute and category, and also the results from the analysis of variance method. The distribution of rental prices has a positive skew 
and is strongly platykurtic, therefore into the GLM framework we look at the distributions that take account of this behaviour. The rented flats from the three large cities, located mainly in the intermediate district and urban periphery district areas, and in blocks with less than 5 floors, are predominant.

The descriptive statistics computed for improvement attributes, Thermal, Heating, Finishing, and overall physical conditions PhCond, indicate low percentages for unfinished flats, and for flats located in buildings with inadequate technical state; the majority of flats are equipped with individual boilers. Examining each attribute separately, the F-test from ANOVA rejects the equality of average rental prices among the categories, for all improvement attributes. The rental prices seem not to vary across categories for the following variables: year of transaction, type of the flat (detached/ non-detached) and floor of the flat. The descriptive statistics suggest, as expected, that the rental prices are significantly lower in Arad than in the other three large cities, and that they are significantly higher in the central area.

Following a careful analysis of the significance of coefficients for dummy variables, in the models including all attributes, the variable PhCond was redefined, as indicated in Table 1. Also, the urban periphery district and suburban areas are considered a single category. The backward selection approach provides the empirical results reported in Table 3; almost the same variables were selected regardless of specification, as the attributes with significant effect on rental prices. The set of significant attributes, in addition to the physical state of the building and finishing, includes: the city, location inside the city, number of rooms/ area, existence of a garage, existence of a balcony, generally included also in the hedonic models for sale prices.

We first examine the M1, M2, and M3 models, considering the number of rooms. According to the AIC information criteria the Gamma-log model performs better than the inverse Gaussian-log model. The in-sample performance of these models is almost the same, as suggested by the MAE, and by the R-square coefficient measuring the proportion of the null deviance accounted for by the model. The physical state of the building and finishing variables are significant in all specifications, but have lower effect than on sale prices.

According to the log-linear model, for a very good physical condition of the building there is a willingness to pay a $10.5 \%$ higher price, as long as the other attributes are the same. As in the case of the sale price, this attribute seems to incorporate the effect of thermal insulation; when it is removed from the model, the thermal insulation has a significant effect on rental prices (Wald test $=$ $6.55 ; \mathrm{p}$-value $=0.01)$. The finishing level of the flat has a significant but not strong effect on rental prices, as long as this variable remains borderline significant. A superior level of finishing in the flat has a marginal effect on rental prices, triggering

Table 3. Summary of hedonic models for rental price

\begin{tabular}{|c|c|c|c|c|c|}
\hline Model & M1 & M2 & M3 & M4 & M5 \\
\hline Variable & Log-linear & Gamma-log & Inv.Gauss.-log & Log-linear & Gamma-log \\
\hline \multicolumn{6}{|l|}{ Finishing } \\
\hline Superior & $1.106 * *(5.7)$ & $1.096^{* *}(4.8)$ & $1.100 *(5.5)$ & $1.118 *(7.9)$ & $1.114 *(7.6)$ \\
\hline Medium & 1.066 & $1.065(3.3)$ & $1.059(2.8)$ & $1.066 * *(3.9)$ & $1.060 *(3.2)$ \\
\hline PhCond2 & $1.103 *(9.4)$ & $1.131^{*}(15.7)$ & $1.140 *(16.7)$ & $1.084 * *(5.6)$ & $1.090 *(8.2)$ \\
\hline \multicolumn{6}{|l|}{ City } \\
\hline Arad & $0.628 *(83.7)$ & $0.660 *(69.3)$ & $0.634 *(98.7)$ & $0.575 *(129.5)$ & $0.612 *(104.5)$ \\
\hline Iasi & $1.052(1.7)$ & $1.082 * *(4.8)$ & $1.080(3.6)$ & $1.065(3.0)$ & $1.100 *(7.2)$ \\
\hline Timisoara & $0.879 *(13.7)$ & $0.893 *(10.2)$ & $0.905^{*}(7.3)$ & $0.904 *(9.6)$ & $0.909 *(8.7)$ \\
\hline \multicolumn{6}{|l|}{ Location } \\
\hline Central & $1.263 *(45.6)$ & $1.266^{*}(45.1)$ & $1.245 *(36.8)$ & $1.199 *(27.8)$ & $1.192 *(29.8)$ \\
\hline Intermediate & $1.064 * *(4.6)$ & $1.051 *(3.7)$ & $1.041(1.9)$ & $1.061 * *(4.7)$ & $1.061 *(4.8)$ \\
\hline Rooms & $1.298 *(94.9)$ & $1.302 *(100.5)$ & $1.299 *(100.3)$ & - & - \\
\hline Area & - & - & - & $1.010 *(159.6)$ & $1.010 *(149.8)$ \\
\hline Garage & $1.290 *(30.5)$ & $1.300 *(33.1)$ & $1.274 *(18.2)$ & $1.182 *(14.1)$ & $1.183 *(14.8)$ \\
\hline Balcony & $1.080 *(8.8)$ & $1.077 *(8.1)$ & $1.074 *(7.4)$ & $1.067 *(6.9)$ & $1.072 *(8.2)$ \\
\hline \multirow[t]{5}{*}{ Intercept } & $147.2^{*}$ & $147.2 *$ & $147.6^{*}$ & $109.7 *$ & $110.9 *$ \\
\hline & $\mathrm{LR}=320.7$ & $\mathrm{LR}=349.1$ & $\mathrm{LR}=324.1$ & $\mathrm{LR}=371.7$ & $\mathrm{LR}=398.6$ \\
\hline & $\mathrm{AIC}=95.3$ & $\mathrm{AIC}=5072.9$ & $\mathrm{AIC}=5086.1$ & $\mathrm{AIC}=44.6$ & $\mathrm{AIC}=5021.5$ \\
\hline & $\mathrm{MAE}=42.85$ & $\mathrm{MAE}=43.25$ & $\mathrm{MAE}=43.38$ & $\mathrm{MAE}=38.56$ & $\mathrm{MAE}=38.74$ \\
\hline & $\mathrm{R} 2=0.50$ & $\mathrm{R} 2=0.51$ & $\mathrm{R} 2=0.49$ & $\mathrm{R} 2=0.55$ & $\mathrm{R} 2=0.56$ \\
\hline
\end{tabular}

Notes: For each model are reported $\operatorname{Exp}(\beta)$ where $\beta$ are the coefficients of explanatory variables, and the Wald test (in parentheses). ${ }^{*}$ Significant at $1 \%,{ }^{* *}$ significant at $5 \%$. For inverse Gaussian-log model including the Area, are obtained: $\mathrm{LR}=351.0, \mathrm{AIC}=5057.3, \mathrm{MAE}=39.6 .2, \mathrm{R} 2=0.53$. 
a price surge of about 10\%. Bala et al. (2014) also conclude that renovated dwellings carry higher monthly rents. Owners are motivated to improve the physical characteristics of properties, in order to rent at higher prices. Tenants are looking for finished flats, to improve their living standards, but are also interested in some improvements that could reduce the cost of utilities.

The number of rooms, existence of a balcony, garage, and location have a significant effect on rental prices. The price of two-room flats is higher roughly by $30 \%$ than the price of one-room flats. Flats from blocks located in the central area carry a significantly higher rent than those from the urban periphery district and suburban areas, roughly by $26 \%$. The lowest rental rates are in Arad, and the highest in Iasi and Cluj-Napoca; in these two cities the rent does not appear to be significantly different, as also suggested by the Student t-test for equality of two means $(t=1.37$; $p$-value $=0.17$ ). These two cities are important university centres, thus a large part of the demand for rental flats comes from students. Due to the small number of rent transactions in each city these statistics should be viewed as indicative.

When the floor area is considered instead of the number of rooms, usually the MAE and Rsquare indicators show better fit; the continuous variables are richer in information than categorical variables. The empirical results from the loglinear model and Gamma-log model are indicated in Table 3 (model M4 and M5). As the estimated hedonic regressions suggest, one additional square meter of floor area triggers a rental price increase of $1 \%$. The overall physical state of the building and finishing variables still remain significant, at $5 \%$ significance level, but the effect of the first variable is slightly lower than in previous specifications.

Overall, both variables, the physical state of the building and finishing works, remain significant regardless the distribution of rental price. The multicollinearity is not an issue as long as no VIF exceeded 3.03. The LR test for omitted variables indicates that the physical state of building $(\mathrm{LR}=$ $9.30, \mathrm{p}$-value $=0.00$ for $\mathrm{M} 1, \mathrm{LR}=5.56, \mathrm{p}$-value $=$ 0.02 for M4), respectively the finishing works (LR $=5.73$, -value $=0.00$ for model M1, and LR $=7.85$, $p$-value $=0.00$ for model M4) are variables that significantly influence the rental price. Using the White' heteroskedasticity robust standard errors, similar results are provided; the variables of interest are still significant.

\section{CONCLUSIONS}

This paper examines a specific segment of the Romanian housing market, namely blocks of flats in the urban area. Similarly to other markets from Central and Eastern Europe, the Romanian real estate market inherits some stock of low-quality blocks of flats, with a small living surface and low comfort, undergoing a process of deterioration. We highlight the steps taken by owners and authorities to improve the housing maintenance, and the living standards in these dwellings. This analysis may contribute to a better understanding of the housing market from Romania and from the CEE countries.

The empirical section investigates whether and to what extent the improvements made to the stock of flats have a significant effect on sale and rental prices. As described in Section 2, the total cost of building modernization and finishing works inside the flats, is about $179 \mathrm{Euro} / \mathrm{m}^{2}$, without VAT, as an average for flats with one or two rooms. On the other hand, in our sample, the average sale price is $906 \mathrm{Euro} / \mathrm{m}^{2}$ for flats with very good physical conditions of the building and super-finishing level inside the flats, respectively $717 \mathrm{Euro} / \mathrm{m}^{2}$ for flats with unsatisfactory physical state of the building and demi-finishing level inside the flats; the difference between these two average prices is 189 Euro $/ \mathrm{m}^{2}$. Overall, the marginal price and the cost of modernization can be considered as being comparable, taking account of the difficulty of accurately estimating the cost and that average values are involved.

Two hedonic analyses were conducted, one for sale transactions and another one for rental transactions, based on samples of flats from blocks located in four large towns from Romania. Hedonic models are estimated in a GLM framework, which considers the following specifications: the loglinear model, Gamma distribution with log link, and inverse Gaussian distribution with log link. Generally, for our data, the empirical results regarding the marginal prices of the improvements attributes are consistent with these specifications. The traditional log-linear and Gamma-log models provided close results in terms of fit and prediction accuracy. The inverse Gaussian-log models lead to a weaker agreement between the actual and predicted prices. The robustness of empirical results was also investigated from other points of view, namely multicollinearity, omitted variables and heteroscedasticity. 
The hedonic models for sale prices suggest that the physical state of the building and finishing works inside the flat have a significant effect on pricing, in all specifications. We can draw some conclusions about the estimates obtained for marginal prices from the log-linear and Gammalog models. The price of flats located in buildings that are classified as very good is higher by $12.7-$ $15.4 \%$, respectively by $5.6-9.1 \%$ for buildings that are classified as good, than the price of flats from blocks in unsatisfactory technical conditions. The implicit marginal price for the existence of finishing works varies between $8 \%$ and $10 \%$. There is a borderline significance for the existence of an individual boiler heating system, in some models the sale price increasing by about $6 \%$. Given the multiplicative form of the hedonic model, the marginal price for both variables, modernization of the building and finishing works inside the flats, suggested by model M1 is about $26.8 \%$ (as $1.154^{*} 1.099=1.268$ ), as long as all the other attributes remain unchanged.

According to the hedonic models for rental price, the physical state of the building and finishing variables have a significant impact on rent in all specifications, but the effect seems to be lower in some models. For a good physical condition of the building there is a willingness to pay a rental price higher by $8.5-13 \%$. A superior-finishing level in the flats has a significant marginal effect on rental price, leading to an increase of about $11 \%$. The existence of thermal insulation does not have a significant coefficient, but the overall physical state variable seems to incorporate the effect of thermal insulation, both in the sale price and rental price models.

As expected, sale and rental prices are first and foremost influenced by the flat size and location. One additional square meter of floor area leads to an increase of about $1.8 \%$ of the sale price, and of $1.0 \%$ of the rental price. The marginal effect of floor area on pricing is higher for sale transactions than for rental transactions. The sales price of two-room flats is higher by about $40 \%$ than that of one-room flats, while the rental price by merely $30 \%$. The location inside the city also has a significant effect on pricing.

Finally, our findings suggest a common set of significant attributes, both for the sale price models and rental price models: the physical state of the building, finishing level, number of rooms/ area, the city, the location inside the city, existence of a balcony.
The preliminary analysis on housing modernization features and the results provided by the empirical research concerning the effects of modernization attributes of flats and buildings (physical characteristics), as well as of location and other attributes, on sale and rental prices, are useful for valuation companies, valuators and public authorities. At the same time, the implications of these findings should be interpreted in light of a number of limitations. Firstly, a larger sample of real estate transactions could be useful in order to further develop our findings. It would bring added value to include additional attributes in the hedonic pricing models in order to increase the explanatory power of the models. Furthermore, future research could extend the analysis to the sub-markets of the four cities, since each city can have some particularities regarding the effects of housing attributes on the sale and rental prices.

\section{ACKNOWLEDGEMENTS}

Collection of data, used in the empirical studies, has been part of a European Social Fund project/ The Sectorial Operational Programme for Human Resources Development 2007-2013. Special acknowledgements to the financial consulting company Napoca Business and especially to one of the associates, Mr. Gliga Alexandru, for the valuable information on the technical and pricing items for the Romanian market.

The authors would like to express their gratitude to the anonymous Referees whose comments have been extremely useful to revise previous versions of the paper, and to the Editor.

\section{REFERENCES}

Abraham, J. M.; Hendershott, P. H. 1996. Bubbles in metropolitan housing markets, Journal of Housing Research 7: 191-207.

Bala, A. P.; Peeters, D.; Thomas, I. 2014. Spatial issues on a hedonic estimation of rents in Brussels, Journal of Housing Economics 25: 104-123. http://dx.doi. org/10.1016/j.jhe.2014.05.002

Berry, J.; McGreal, S.; Stevenson, S.; Young, J.; Webb, J. R. 2003. Estimation of apartment submarkets in Dublin, Ireland, Journal of Real Estate Research 25(2): 159-170.

Blackley, D. M.; Follain, J. R.; Lee, H. 1986. An evaluation of hedonic price indexes for 34 large SMSAs, American Real Estate and Urban Economics Association Journal 14(Summer): 179-205. http://dx.doi. org/10.1111/1540-6229.00382

BPIE. 2014. BPIE Data Hub for Energy Performance of Buildings. Database [online]. Buildings Performance 
Institute Europe (BPIE). Available at: http://www. buildingsdata.eu/data-search [accessed 1 October 2014]

Brouen, D.; Kok, N. 2011. On the economics of energy labels in the housing market, Journal of Environmental Economics and Management 62(2): 166-179. http://dx.doi.org/10.1016/j.jeem.2010.11.006

Colleta, M. 2013. Household non-financial wealth: methodological aspects and international comparisons [online]. Organization for Economic Co-operation and Development. Available at: http://search.oecd.org/officialdocuments/publicdisplaydocumentpdf/?cote $=\mathrm{C}$ $\mathrm{OM} / \mathrm{STD} / \mathrm{DAF}(2013) 15 \&$ docLanguage $=\mathrm{En}$ [accessed 18 January 2014]

Ekeland, I.; Heckman, J. J.; Nesheim, L. 2004. Identification and estimation of hedonic models, Journal of Political Economy 112(1): 60-109. http://dx.doi. org/10.1086/379947

European Mortgage Federation. 2012. Key figures [online]. Available at: http://www.hypo.org/Content/Default.asp?PageID=414 [accessed 1 October 2014]

Eurostat. 2013. Handbook on residential property price indices (RPPIs) [Online]. Eurostat Methodologies \& Working papers, Publications Office of the European Union. Available at: http://epp.eurostat.ec.europa.eu/ cache/ity_offpub/ks-ra-12-022/en/ks-ra-12-022-en.pdf [accessed 22 February 2014]

Eurostat. 2014. Income and living conditions [online]. Eurostat Database. Available at: http://ec.europa.eu/ eurostat/web/income-and-living-conditions/data/database [accessed 1 October 2014]

Fabozzi, F. J.; Shiller, R. J.; Tunaru, R. S. 2010. Property derivatives for managing European real-estate risk, European Financial Management 16(1): 8-26. http://dx.doi.org/10.1111/j.1468-036X.2009.00528.x

Fox, G. 2008. Applied regression analysis and generalized linear models. Sage Publications.

Frew, J.; Jud, G. D. 2003. Estimating the value of apartment buildings, Journal of Real Estate Research 25(1): 77-86.

Fuerst, F.; McAllister, P.; Nanda, A.; Wyatt, P. 2015. Does energy efficiency matter to home-buyers? An investigation of EPC ratings and transaction prices in England, Energy Economics 48: 145-156. http:// dx.doi.org/10.1016/j.eneco.2014.12.012

Ghysels, E.; Plazzi, A.; Valkanov, R. 2007. Valuation in US commercial real estate, European Financial Management 13(3): 472-497. http://dx.doi.org/10.1111/ j.1468-036X.2007.00369.x

Goodhart, C. A. E.; Hofmann, B. 2008. House prices, money, credit, and the macroeconomy, Oxford Review of Economic Policy 24(1): 180-205. http://dx.doi. org/10.1093/oxrep/grn009

Government Ordinance. 2009. Government Ordinance No. 18/2009 concerning the increase of the energetic efficiency of flats [online]. Available at: http://www. dreptonline.ro/legislatie/oug_cresterea_performantei_energetice_blocurilor_locuinte_18_2009.php [accessed 1 October 2014]

Government Decision. 2010. Government Decision No. $363 / 2010$ concerning the approval of cost standards for investments funded by public resources [online].
Available at: http://lege5.ro/en/Gratuit/geztimrqga/ hotararea-nr-363-2010-privind-aprobarea-standardelor-de-cost-pentru-obiective-de-investitii-finantatedin-fonduri-publice [accessed 1 October 2014]

Helbich, M.; Jochem, A.; Mücke, W.; Höfle, B. 2013. Boosting the predictive accuracy of urban hedonic house price models through airborne laser scanning, Computers, Environment and Urban Systems 39: 81-92. http://dx.doi.org/10.1016/j.compenvurbsys.2013.01.001

Helbich, M.; Brunauer, W.; Vaz, E.; Nijkamp, P. 2014. Spatial heterogeneity in hedonic house price models: the case of Austria, Urban Study 51: 390-411. http:// dx.doi.org/10.1177/0042098013492234

Hepsen, A.; Vatansever, M. 2012. Relationship between residential property price index and macroeconomic indicators in Dubai housing market, International Journal of Strategic Property Management 16(1): 71-84. http://dx.doi.org/10.3846/164871 5X.2011.602756

Herath, S.; Choumert, J.; Maier, G. 2015. The value of the greenbelt in Vienna: a spatial hedonic analysis, The Annals of Regional Science 54(2): 349-374. http://dx.doi.org/10.1007/s00168-015-0657-1

Hoesli, M.; Thion, B.; Watkins, C. 1997. An hedonic investigation of the rental value of apartments in central Bordeaux, Journal of Property Research 14: 15-26. http://dx.doi.org/10.1080/095999197368735

Huynh-Olesen, D. T.; Steiner, K.; Hildebrandt, A.; Wagner, K. 2013. Residential property prices in Central, Eastern and Southeastern European countries: the role of fundamentals and transition-specific factors, Focus on European Economic Integration Q2/13, OeNB, 52-76.

Jones, C. 2002. The definition of housing market area and strategic planning, Urban Studies 39(3): 549-564. http://dx.doi.org/10.1080/00420980220112829

Kryvobokov, M.; Wilhelmsson, M. 2007. Analysing location attributes with a hedonic model for apartment prices in Donetsk, Ukraine, International Journal of Strategic Property Management 11(3): 157-178. http://dx.doi.org/10.1080/1648715X.2007.9637567

Lamont, O.; Stein, J. 1999. Leverage and house price dynamics in US cities, Rand Journal of Economics 30: 498-514. http://dx.doi.org/10.2307/2556060

McCulloch, C. E.; Searle, S. R. 2001. Generalized, linear, and mixed models. New York: John Wiley and Sons.

National Institute of Statistics. 2002. The 2002 Population and Housing Census [online]. Available at: http://www.insse.ro/cms/files/RPL2002INS/index rpl2002.htm [accessed 1 October 2014]

National Institute of Statistics. 2011. The 2011 Population and Housing Census [online]. Available at: http://www.recensamantromania.ro/rezultate-2/ [accessed 1 October 2014]

Palacin, J.; Shelburne, R. 2005. The private housing market in Eastern Europe and CIS, UNECE Discussion Paper No. 2005-5, UNECE, Geneva.

Portnov, B. A.; Odish, Y.; Fleishman, L. 2005. Factors affecting housing modifications and housing pricing: a case study of four residential neighborhoods in Haifa, Israel, Journal of Real Estate Research 27(4): 371-394. 
Pasztor, G., Peter, L. 2009. Urban housing problem in Romania: the legacy of communist block of flats [Online]. Available at: http://www.gla.ac.uk/media/ media_129752_en.pdf [accessed 1 September 2013].

Realmedia Network. 1994-2014. Indicele imobiliare. ro [online]. Available at: http://www.imobiliare.ro/ indicele-imobiliare-ro [accessed 1 October 2014]

Rehm, M.; Filippova, O.; Stone, J. 2006. The influence of vintage on house value, Pacific Rim Property Research Journal 12(3): 232-253. http://dx.doi.org/10.1 080/14445921.2006.11104208

Rosen, S. 1974. Hedonic prices and implicit markets: product differentiation in pure competition, Journal of Political Economy 82(1): 34-55. http://dx.doi. org/10.1086/260169

Selim, H. 2009. Determinants of house prices in Turkey: hedonic regression versus artificial neural network, Expert Systems with Applications 36: 2843-2852. http://dx.doi.org/10.1016/j.eswa.2008.01.044

Sirmans, G. S.; Macpherson, D. A.; Zietz, E. N. 2005. The composition of hedonic pricing models, Journal of Real Estate Literature 13(1): 3-46.

Schiopu, C. 2011. Catalog Costuri de reconstructie/costuri de inlocuire - cladiri industriale, comerciale si agricole, constructii speciale [Reconstruction/ replacement costs catalog - industrial, commercial and agricultural buildings, special constructions]. Bucharest: IROVAL.

Sipos, C.; Crivii, A. 2008. A linear regression model for real estate appraisal, The Valuation Journal 2(5): 49-57.
Song, H. S.; Wilhelmsson, M. 2010. Improved price index for condominiums, Journal of Property Research 27(1): 39-60. http://dx.doi.org/10.1080/09599916.2010.500394

Stevenson, S. 2004. New empirical evidence on heteroskedasticity in hedonic housing models, Journal of Housing Economics 13(2): 136-153. http://dx.doi. org/10.1016/j.jhe.2004.04.004

Troy, A.; Grove, J. M. 2008. Property values, parks, and crime: a hedonic analysis in Baltimore, MD, Landscape and Urban Planning 87: 233-245. http://dx.doi. org/10.1016/j.landurbplan.2008.06.005

White, H. 1980. A heteroskedasticity-consistent covariance matrix estimator and a direct test for heteroskedasticity, Econometrica 48(4): 817-838. http:// dx.doi.org/10.2307/1912934

Wilhelmsson, M. 2008. House price depreciation rates and level of maintenance, Journal of Housing Economics 17(1): 88-101. http://dx.doi.org/10.1016/j. jhe.2007.09.001

Willmott, C. J.; Matsuura, K. 2005. Advantages of the mean absolute error (MAE) over the root mean square error (RMSE) in assessing average model performance, Climate Research 30: 79-82. http://dx.doi. org/10.3354/cr030079

Wilson, B.; Frew, J. 2007. Apartment rents and locations in Portland, Oregon: 1992-2002, Journal of Real Estate Research 29(2): 201-217.

Zietz, J.; Zietz, E.; Sirmans, G. 2008. Determinants of house prices: a quantile regression approach, Journal of Real Estate Finance and Economics 37(4): 317-333. http://dx.doi.org/10.1007/s11146-007-9053-7 